\title{
Complex Endometrial Hyperplasia: Prevalence and Risk Factors for coexisting Endometrial Carcinoma
}

\author{
${ }^{1}$ Munazza Akhtar, ${ }^{2}$ Uzma Chishti, ${ }^{3}$ Aliya B Aziz, ${ }^{4}$ Iffat Ahmad, ${ }^{5}$ Sheikh Irfan
}

\begin{abstract}
Objective: This study was planned to observe the prevalence of endometrial carcinoma in patients with complex endometrial hyperplasia. It has also assessed the risk factors for concomitant endometrial carcinoma.
\end{abstract}

Materials and methods: Retrospective analysis of 71 patients with complex endometrial hyperplasia surgically treated between 1995 and 2015 in Aga Khan University Hospital, Karachi, Pakistan, was performed.

Results: The prevalence rate of concurrent endometrial carcinoma in patients with endometrial hyperplasia was 34\%. The rate for concurrent endometrial carcinoma in patients with complex hyperplasia with atypia was $49 \%$ as compared with $4.2 \%$ in patients without atypia. Cancer risk was significantly related to menopause $(p=0.043)$ and presence of atypia $(p=0.0005)$.

Multivariate analysis to adjust for confounders revealed that cytological atypia [odds ratio (OR), 17.12; 95\% confidence interval (Cl), 2.07-141.42], menopause (OR, 2.07; 95\% Cl, $0.51-7.91$ ), and hypertension (OR, 1.67; 95\% Cl, 0.51-5.44) were independent risk factors for endometrial hyperplasia coexisting with endometrial carcinoma

Conclusion: The optimal management for menopausal women with complex hyperplasia along with atypia should be surgical intervention. We recommend that these women should be managed in centers where expertise and skills of adequate surgical staging are available.

Keywords: Complex endometrial hyperplasia, Endometrial carcinoma, Risk factors.

How to cite this article: Akhtar M, Chishti U, Aziz AB, Ahmad I, Irfan S. Complex Endometrial Hyperplasia: Prevalence and Risk Factors for coexisting Endometrial Carcinoma. J South Asian Feder Menopause Soc 2018;6(1):62-64.

Source of support: Nil

Conflict of interest: None

Date of received: 10 January 2018

Date of acceptance: 27 January 2018

Date of publication: August 2018

${ }^{1,2,4}$ Assistant Professor, ${ }^{3}$ Associate Professor, ${ }^{5}$ Senior Instructor

${ }^{1-5}$ Department of Obstetrics and Gynecology, The Aga Khan University, Karachi, Sindh, Pakistan

Corresponding Author: Aliya B Aziz, Associate Professor Department of Obstetrics and Gynecology, The Aga Khan University, Karachi, Sindh, Pakistan, Phone: +00922134864646 e-mail: azizaliya@hotmail.com

\section{INTRODUCTION}

Endometrial hyperplasia is the proliferation of glands that are irregular in size and shape with an increase in the glands/stroma ratio. It is thought to be the precursor of endometrial carcinoma, but concurrent endometrial carcinoma in patients with endometrial hyperplasia is seen quite often. ${ }^{1}$ It can occur at any stage of reproductive life of females, but is more common at about the age of menopause.

Endometrial hyperplasia is classified into four categories according to the World Health Organization system, including simple hyperplasia without atypia, simple hyperplasia with atypia, complex hyperplasia without atypia, and complex hyperplasia with atypia. ${ }^{2}$

The most probable cause of such changes is excess or unopposed estrogenic stimuli. It could be asymptomatic or present as abnormal or postmenopausal vaginal bleeding. Transvaginal sonography and endometrial biopsy are often used for the diagnosis of this condition. ${ }^{3}$

Endometrial hyperplasia can be treated medically with progesterone; however, its surgical management is justified due to its risk of progression to carcinoma. For clinical management, the presence of atypical cytology is most important. It indicates an increased risk of subsequent carcinoma and raises suspicions about the possibility of a coexistent carcinoma. Carcinoma may be found in $40 \%$ of hysterectomy specimens performed for atypical hyperplasia. ${ }^{4,5}$

Cancer that arises on a background of endometrial hyperplasia appears to be of a low grade and at a lesser stage; so, the 5-year survival is more in these patients. ${ }^{6}$

This study was intended to see the prevalence of endometrial carcinoma in patients with tissue biopsy diagnosis of endometrial hyperplasia in our population and setup. The study has also evaluated the coexisting risk factors for endometrial carcinoma.

\section{MATERIALS AND METHODS}

After the approval of the Institutional Review Board,we conducted a retrospective cross-sectional analyses of 71 patients with complex endometrial hyperplasia. These patients underwent surgical intervention for the above-mentioned pathology at the Obstetrics and Gynecology Department of The Aga Khan University hospital between 1995 and 2015. 
Prevalence and Risk Factors for coexisting Endometrial Carcinoma

Medical records of all patients were reviewed and relevant demographic, clinical, surgical, and pathologic information was acquired. A preoperative pathological diagnosis of endometrial hyperplasia was determined by office endometrial biopsy or hysteroscopy in patient biopsy in all patients.

A total of 24 women were found to have endometrial carcinoma in their hysterectomy specimen. Based on this factor, all women were divided into two groups: One with concurrent carcinoma $(n=24)$ and one without carcinoma $(n=47)$. The correlation of risk factors was analyzed between the two groups.

The clinical and pathological characteristics of all 24 patients with diagnosis of concurrent carcinoma were studied.

For data recording and analysis, Statistical Package for the Social Sciences version 19 was used. Chi-squared test was used to compare categorical variables. Means were calculated and compared using t-test. Subsequently, multivariate analysis of risk factors was performed by binary logistic regression to obtain the adjusted OR and 95\% CI. Statistical significance was defined as a $\mathrm{p}$-value of $<0.05$.

\section{RESULTS}

The prevalence rate of concurrent endometrial carcinoma in patients with endometrial hyperplasia was $34 \%$. Out of 71 patients with endometrial hyperplasia on biopsy, 24 were found to be the case of endometrial carcinoma on final histopathology after hysterectomy. As shown in Table 1 , there is no statistical difference in age, body mass index (BMI), parity, and diabetes among the two groups.

The rate for concurrent endometrial carcinoma in patients with complex hyperplasia with atypia was $49 \%$ as compared with $4.2 \%$ in patients without atypia. The risk of cancer was significantly related to menopause $(p=0.043)$ and presence of atypia in biopsy specimen $(\mathrm{p}=0.0005)$.

Multivariate analysis to adjust for confounders revealed that cytological atypia (OR, 17.12; 95\% CI, 2.07-141.42), menopause (OR, 2.07; 95\% CI, 0.51-7.91), and hypertension (OR, 1.67; 95\% CI, 0.51- .44) were independent risk factors for endometrial hyperplasia concomitant with endometrial carcinoma as shown in Table 2.

\section{DISCUSSION}

The prime apprehension in the management of women who have been diagnosed with endometrial hyperplasia is the risk of underlying simultaneous carcinoma. $5,7,8$ This study endorses the existing epidemiologic data about coexisting carcinoma in patients with complex endometrial hyperplasia. ${ }^{3,9}$

Endometrial hyperplasia usually affects women at perimenopausal age, whereas the risk of concomitant
Table 1: Characteristics of patients with no carcinoma and endometrial carcinoma classified by final pathology of hysterectomy

\begin{tabular}{llll}
\hline Variables & $\begin{array}{l}\text { No carcinoma } \\
(n=47)\end{array}$ & $\begin{array}{l}\text { Endometrial } \\
\text { carcinoma }(n=24)\end{array}$ & $p$-value \\
\hline Age $($ years $)$ & $54.15 \pm 7.99$ & $54.04 \pm 6.16$ & $0.95^{\dagger}$ \\
BMl $\left(\mathrm{kg} / \mathrm{m}^{2}\right)$ & $35.88 \pm 6.17$ & $36.99 \pm 8.47$ & $0.53^{\ddagger}$ \\
Menopause & & & $0.043^{\ddagger}$ \\
Menstruation & $18(40.4 \%)$ & $4(16.7 \%)$ & \\
Postmenopause & $28(59.6 \%)$ & $20(83.3 \%)$ & \\
Parity & & & \\
Nulliparous & $3(6.4 \%)$ & $1(4.2 \%)$ & $0.61^{\ddagger}$ \\
$\leq 4$ & $28(59.6 \%)$ & $12(50 \%)$ & \\
$>4$ & $16(34 \%)$ & $11(45.8 \%)$ & \\
Type of surgery & & & \\
TAH & $2(4.3 \%)$ & $0(0 \%)$ & \\
TAH + BSO & $45(95.7 \%)$ & $24(100 \%)$ & \\
Diabetic & & & $0.60^{\ddagger}$ \\
Yes & $6(12.8 \%)$ & $4(16.7 \%)$ & \\
No & $41(87.2 \%)$ & $20(83.3 \%)$ & \\
Hypertension & & & $0.15^{\ddagger}$ \\
Yes & $25(53.2 \%)$ & $17(70.8 \%)$ & \\
No & $22(46.8 \%)$ & $7(29.2 \%)$ & $0.0005^{\ddagger}$ \\
Histopathology subtype & & \\
Atypia & $24(51.1 \%)$ & $23(95.8 \%)$ & \\
Nonatypia & $23(48.9 \%)$ & $1(4.2 \%)$ & \\
\hline
\end{tabular}

Data presented as mean and standard deviation; ${ }^{\dagger}$ Independent t-test used; ${ }^{\ddagger}$ Chi-square test used; TAH: Total abdominal hysterectomy; BSO: Bilateral salpingo-oophorectomy

Table 2: Multivariate and univariate analysis of risk factors for coexistence of endometrial hyperplasia and endometrial carcinoma

\begin{tabular}{|c|c|c|c|c|}
\hline \multirow[t]{2}{*}{ Risk factors } & \multicolumn{2}{|c|}{ Univariate } & \multicolumn{2}{|c|}{ Multivariate } \\
\hline & OR & $95 \% \mathrm{Cl}$ & OR & $95 \% \mathrm{Cl}$ \\
\hline \multicolumn{5}{|l|}{ Menopause } \\
\hline Menstruation & Ref & $1.0-11.51$ & Ref & \\
\hline Postmenopause & 3.39 & & 2.07 & $0.51-7.91$ \\
\hline \multicolumn{5}{|l|}{ Hypertension } \\
\hline Yes & 2.14 & $0.75-6.10$ & 1.67 & $0.51-5.44$ \\
\hline No & Ref & & Ref & \\
\hline \multicolumn{5}{|c|}{ Histopathology subtype } \\
\hline Atypia & 22.04 & $2.75-176.82$ & 17.12 & $2.07-141.42$ \\
\hline Nonatypia & Ref & & Ref & \\
\hline
\end{tabular}

carcinoma is not affected by age. Previous data and studies show that increased weight/BMI is interrelated with increased risk of carcinoma, ${ }^{9}$ whereas, in our study population, it does not turn out to be significant. Our study also confirms the association of hypertension in our population, but negates the positive association of diabetes with concomitant endometrial carcinoma. ${ }^{3,10}$

The patients of endometrial hyperplasia can present clinically with abnormal uterine bleeding or with postmenopausal bleeding. As shown in previous studies, the risk of underlying carcinoma is more in women of postmenopausal status. ${ }^{11}$ 
The prevalence of concurrent carcinoma among the patients with complex hyperplasia ranged between 17 and $52 \%$ in several studies. ${ }^{4,5}$ In our study, we observed a prevalence of $34 \%$. The rate for coexisting endometrial carcinoma in patients with complex hyperplasia with atypia was $49 \%$ as compared with $4.2 \%$ in patients without atypia. These results are well-matched with previous studies. ${ }^{4,12,13}$

In addition to cytological atypia, menopausal status and hypertension were shown to be independent risk factors by multivariate analysis.

The concluding histopathology report of all the women with coexisting endometrial carcinoma in our group exhibited grades 1 or 2 . This is also consistent with Merisio et $\mathrm{al}^{5}$ and other studies. ${ }^{14}$

Endometrial hyperplasia is a disease that can affect women of all ages. This study supports the view that women with atypical hyperplasia during menopausal years should be managed surgically at the oncology centers. This is to ensure that adequate expertise for surgical staging is available. Further research should be directed about effectiveness of conservative or medical approaches to the management of complex hyperplasia without atypia. It is of substantial importance due to uncertainties of natural history of this disease ${ }^{7}$ and effectiveness of conservative management strategies in this condition. This can only be reliably assessed in randomized controlled trial setting. ${ }^{15,16}$

The strengths that made our study valid and applicable are standardized pro forma and International Classification of Diseases, Ninth Revision coding system. The pro forma was specially designed and the study population is methodically selected through this coding system.

The lack of control group was the foremost limitation; secondly, the data were retrospective and taken from a single, large, teaching hospital of one city only.

\section{REFERENCES}

1. Montgomery BE, Daum GS, Dunton CJ. Endometrial hyperplasia: a review. Obstet Gynecol Surv 2004 May;59(5): 368-378.

2. Hahn HS, Chun YK, Kwon YI, Kim TJ, Lee KH, Shim JU, Mok JE, Lim KT. Concurrent endometrial carcinoma following hysterectomy for atypical endometrial hyperplasia. Eur J Obstet Gynecol Reprod Biol 2010 May;150(1):80-83.

3. Clark TJ, Neelakantan D, Gupta JK. The management of endometrial hyperplasia: an evaluation of current practice. Eur J Obstet Gynecol Reprod Biol 2006 Apr;125(2): 259-264.

4. Chen YL, Cheng WF, Lin MC, Huang CY, Hsieh CY, Chen CA. Concurrent endometrial carcinoma in patients with a curettage diagnosis of endometrial hyperplasia. J Formos Med Assoc 2009 Jun;108(6):502-507.

5. Merisio C, Berretta R, De Ioris A, Pultrone DC, Rolla M, Giordano G, Tateo S, Melpignano M. Endometrial cancer in patients with preoperative diagnosis of atypical endometrial hyperplasia. Eur J Obstet Gynecol Reprod Biol 2005 Sep;122(1):107-111.

6. Trimble CL, Kauderer J, Zaino R, Silverberg S, Lim PC, Burke JJ 2nd, Alberts D, Curtin J. Concurrent endometrial carcinoma in women with a biopsy diagnosis of atypical endometrial hyperplasia: a Gynecologic Oncology Group study. Cancer 2006 Feb;106(4):812-819.

7. Lacey JV Jr, Sherman ME, Rush BB, Ronnett BM, Ioffe OB, Duggan MA, Glass AG, Richesson DA, ChatterjeeN, Langholz B. Absolute risk of endometrial carcinoma during 20-year follow-up among women with endometrial hyperplasia. J Clin Oncol 2010 Feb;28(5):788-792.

8. Leitao MM Jr, Kehoe S, Barakat RR, Alektiar K, Rabbitt C, Chi DS, Soslow RA, Abu-Rustum NR. Endometrial sampling diagnosis of FIGO grade 1 endometrial adenocarcinoma with a background of complex atypical hyperplasia and final hysterectomy pathology. Am J Obstet Gynecol 2010 Mar;202(3):278e1-278e6.

9. Beavis AL, CheemaS,HolschneiderCH,Duffy EL,Amneus MW. Almost half of women with endometrial cancer or hyperplasia do not know that obesity affects their cancer risk. Gynecol Oncol Rep 2015 Jul;13:71-75.

10. Matsuo K, Ramzan AA, Gualtieri MR, Mhawech-Fauceglia P, Machida H, Moeini A, Dancz CE, Ueda Y, Roman LD. Prediction of concurrent endometrial carcinoma in women with endometrial hyperplasia. Gynecol Oncol 2015 Nov;139(2): 261-267.

11. Rakha E, Wong SC, Soomro I, Chaudry Z, Sharma A, Deen S, Chan S, Abu J, Nunns D, Williamson K, et al. Clinical outcome of atypical endometrial hyperplasia diagnosed on an endometrial biopsy: institutional experience and review of literature. Am J Surg Pathol 2012 Nov;36(11):1683-1690.

12. Janicek MF, Rosenshein NB. Invasive endometrial cancer in uteri resected for atypical endometrial hyperplasia. Gynecol Oncol 1994 Mar;52(3):373-378.

13. Bilgin T, Ozuysal S, Ozan H, Atakan T. Coexisting endometrial cancer in patients with a preoperative diagnosis of atypical endometrial hyperplasia. J Obstet Gynaecol Res 2004 Jun;30(3):205-209.

14. Matias-Guiu X, Catasus L, Bussaglia E, Lagarda H, Garcia A, Pons C, Muñoz J, Argüelles R, Machin P, Prat J. Molecular pathology of endometrial hyperplasia and carcinoma. Hum Pathol 2001 Jun;32(6):569-577.

15. Farquhar CM, Lethaby A, Sowter M, Verry J, Baranyai J. An evaluation of risk factors for endometrial hyperplasia in premenopausal women with abnormal menstrual bleeding. Am J Obstet Gynecol 1999 Sep;181(3):525-529.

16. Salman MC, Usubutun A, Boynukalin K, Yuce K. Comparison of WHO and endometrial intraepithelial neoplasia classifications in predicting the presence of coexistent malignancy in endometrial hyperplasia. J Gynecol Oncol 2010 Jun;21(2): 97-101. 